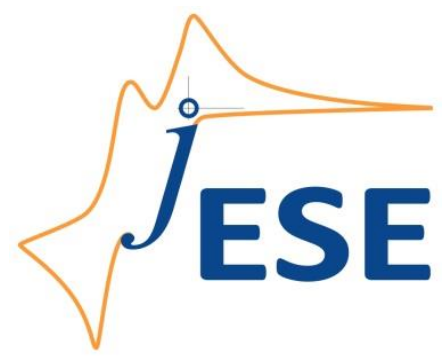

Open Access: ISSN 1847-9286

www.jESE-online.org

Original scientific paper

\title{
Anodic oxidation of oxytetracycline: Influence of the experimental conditions on the degradation rate and mechanism
}

\author{
Annabel Fernandes ${ }^{\bowtie}$, Catarina Oliveira, Maria J Pacheco, Lurdes Ciríaco and \\ Ana Lopes
}

UMTP and Department of Chemistry, University of Beira Interior, 6201-001 Covilhã, Portugal

${ }^{\otimes}$ Corresponding author: E-mail: annabelf@ubi.pt; Tel.: +351-275-329-259; Fax: +351-275-319-730

Received: August 19, 2014; Revised: September 1, 2014; Published: December 6, 2014

\begin{abstract}
The anodic oxidation of oxytetracycline was performed with success using as anode a boron-doped diamond electrode. The experiments were conducted in batch mode, using two different electrochemical cells: an up-flow cell, with recirculation, that was used to evaluate the influence of recirculation flow rate; and a stirred cell, used to determine the influence of the applied current density. Besides oxytetracyclin electrodegradation rate and mineralization extent, oxidation by-products were also assessed. Both the flow rate and the applied current density have shown positive influence on the oxytetracycline oxidation rate. On the other hand, the mineralization degree presented the highest values at the lowest flow rate and the lowest current density tested. The main oxidation by-products detected were oxalic, oxamic and maleic acids.
\end{abstract}

\section{Keywords}

Tetracyclines; BDD; antibiotics; pharmaceutical compounds; electrochemical degradation

\section{Introduction}

The increasing use of drugs has become a new environmental problem, which has aroused great concern in recent years. Although these compounds are found in very low concentrations in the environment, there is still a lack of information about the long-term risks that the presence of a wide variety of drugs can bring to ecosystems and to human health. These drugs are continuously introduced into the environment due to their domestic, hospital and veterinary use, and its presence has been detected in wastewaters [1-4]. Its potential biological activity associated 
with low removal during conventional wastewater treatment processes, can lead to adverse environmental effects, including the contamination of soil and water resources $[5,6]$.

Among these drugs, tetracyclines are one of the most widely used in the prophylaxis and therapy of human and animal infections and also at subtherapeutic levels in animal feed as growth promoters $[7,8]$. Tetracyclines are considered bacteriostatic antibiotics, although they have also various non-antibiotic properties. They are characterized by a four ring structure with a carboxamide functional group and by several ionizable functional groups $[8,9]$. As a result of the waste disposal, the drug is transferred to different environmental compartments (water, sediment, soil) and can contaminate trophic network, transitioning into food and cause negative effects on natural resources, including the effects on microbial community structure and selection of strains with antibiotic resistance [10-12]. The presence of tetracyclines in several environmental matrices has been investigated and the evidence of their existence has been reported [8,13-15]. This is due to the fact that antibiotics are very resistant to biodegradation..

In recent years, there has been a growing awareness about pollution caused by pharmaceutical wastes, including antibiotics $[16,17]$. Biological processes, the most economical for wastewater treatment, have been extensively studied, but they are ineffective in the removal of recalcitrant compounds with poor biodegradability $[17,18]$. Some physical and physicochemical techniques, such as coagulation, flocculation, adsorption, ultrafiltration and reverse osmosis, have been successfully employed to remove recalcitrant pollutants. However, these conventional treatments simply transfer pollutants from one phase to another, resulting in secondary pollution $[17,19]$.

New technologies based on the application of advanced oxidation processes have been reported in the treatment of effluents containing tetracycline [20-37]. Tetracycline degradation efficiency obtained by photo-Fenton processes in the treatment of wastewaters and surface waters was reported by Bautitz and Nogueira [21]. Results showed that the photo-Fenton process under solar radiation can be applied in the degradation of tetracycline present in surface water samples or even in more complex samples, such as effluent from sewage treatment plants. However, the processes that involve photolysis should only be applied to bleached effluents, since the color prevents the efficient propagation of radiation. Li et al. [23] studied the effect of different $\mathrm{pH}$ values on oxytetracycline degradation by ozonation in aqueous solution and found that this technique had potential to be used as a partial step in combined treatment of pharmaceutical effluents containing high concentrations of oxytetracycline. The removal rates increased as a result of high decomposition rates, favored by $\mathrm{pH}$ increase. However, bioluminescence results indicate that after partial ozonation, byproducts of oxytetracycline have a higher toxicity than the parent compound. Jiao et al. [22] and Shaojun et al. [24] studied the degradation of tetracyclines by photolysis and reported high COD removals, of $80 \%$, but very low TOC removal, about $14 \%$, which indicated the production of intermediate compounds. On their studies, it was also found that the toxicity of the treated effluent was higher than in the original effluent. Photocatalysis studies applied to the treatment of waters with low loads of organic matter, such as rivers, ground water and drinking water, containing tetracyclines have been performed by several authors and high removals were obtained, indicating that this method is promising for this type of waters [20,35].

Electrochemical processes have shown to be effective for the treatment of effluents containing refractory and toxic organic pollutants [38-41]. Furthermore, they are an effective, versatile, easy and clean technology $[39,42]$. For all these reasons, this technology has been applied to remove tetracycline under different experimental conditions. Removals above $90 \%$ were achieved using 
$\mathrm{Ti} / \mathrm{RuO}_{2}-\mathrm{IrO}_{2}$ anodes [25] and $\mathrm{Ti} / \mathrm{IrO}_{2}$ anodes [29]. Despite these good results in tetracyclines removal, no significant levels of mineralization were achieved using these active anodes. In the last decade, BDD anode, a non-active anode, is being widely used. It has several advantages, namely good chemical and electrochemical stability, extended lifetime and a high overpotential for water decomposition, being known for its ability to promote complete mineralization of a wide range of organic pollutants $[39,43-47]$ due to the hydroxyl radicals formed from water decomposition on the electrode surface. Brinzila et al. [30] reported an electrodegradation study of tetracycline on BDD anode where removals of $93 \%$ and $87 \%$ were obtained for COD and TOC, respectively. These authors also studied the influence on the degradation rate of initial $\mathrm{pH}$, applied current intensity and electrolyte added [37]. It was observed that an increase in current density leads to a decrease in the current efficiency of the process and the complete removal of tetracycline was much faster in the presence of chloride ions that promoted the complete degradation of this antibiotic in 30 min. The effect of different anode materials in both electrochemical oxidation and electro-Fenton processes on the oxidation of tetracycline was investigated by Oturan et al. [36]. They have reported that processes using BDD anode demonstrated superior oxidation/mineralization power. Almost total mineralization (TOC removal up to $98 \%$ ) of $100 \mathrm{mg} \mathrm{L}^{-1}$ of tetracycline solutions was achieved after $6 \mathrm{~h}$ treatment with BDD anode.

Considering the good results obtained with the BDD anode, in the present study it is proposed its use in the electrochemical degradation of oxytetracycline, an antibiotic from the tetracycline family, widely used in intensive animal husbandry to treat enteric and respiratory diseases. The influence of the hydrodynamics inside the electrochemical cell on the rate of electrodegradation and mineralization of oxytetracycline was studied and the oxidation by-products were also assessed, in order to establish the degradation mechanism.

\section{Experimental}

Oxytetracycline (OTC) used in this study was purchased from Sigma Aldrich (purity $99 \%$ ), with the chemical formula $\mathrm{C}_{22} \mathrm{H}_{24} \mathrm{~N}_{2} \mathrm{O}_{9} \cdot 2 \mathrm{H}_{2} \mathrm{O}$ (Table 1 ), and used without further purification.

Oxytetracycline degradation experiments were conducted in batch mode using two different electrochemical cells. The first set of assays was performed in an up-flow electrochemical cell, with recirculation, composed by a BDD anode with an area of $20 \mathrm{~cm}^{2}$ and a stainless steel cathode with identical area, using $250 \mathrm{~mL}$ of solution. The recirculation of the solution was enabled by a centrifugal pump, Pan World Magnet, Model: NH-30PX, Pan World Co., Ltd. Tokyo, Japan, which allowed the evaluation of different flow rates: 37, 75, 100 and $120 \mathrm{~L} \mathrm{~h}^{-1}$. The applied current density was kept constant at $20 \mathrm{~mA} \mathrm{~cm}^{-2}$. The second set of assays was conducted in batch mode, with stirring, in a cell containing a BDD anode, with an immersed area of $10 \mathrm{~cm}^{2}$, and a stainless steel cathode, with identical area. $200 \mathrm{~mL}$ of solution were used in each run. In order to study the oxidation mechanism and identify the by-products, assays were performed applying different current densities: $2.5,5,7.5,10,20$ and $30 \mathrm{~mA} \mathrm{~cm}$. The experimental conditions used are summarized in Table 1.

For all the experiments performed, the initial oxytetracycline concentration was $100 \pm 10 \mathrm{mg} \mathrm{L}^{-1}$. The assays were conducted at room temperature $\left(25 \pm 2{ }^{\circ} \mathrm{C}\right)$, adding as support electrolyte anhydrous sodium sulfate (Merck, $99.5 \%$ ), in a concentration of $5 \mathrm{~g} \mathrm{~L}^{-1}$. A GW, Lab DC, model GPS-3030D (0-30 V, 0-3 A), was used as power supply. The assays were performed in duplicate, and the values presented for the parameters used to follow the assays are the mean values. 
Degradation tests were followed by total organic carbon (TOC) and total nitrogen (TN), measured in a Shimadzu TOC-V CPH analyzer combined with a TNM-1 unit, by chemical oxygen demand (COD), performed using closed reflux and titrimetric method, and by ammonia nitrogen (AN), using a Vapodest 20s distillation system from Gerhardt, according to standard procedures [48]. UV-Visible absorption spectra were also performed, with measurements made between 200 and $800 \mathrm{~nm}$, using a Shimatzu UV-1800 spectrophotometer. High performance liquid chromategraphy (HPLC) was performed using a Shimadzu 20A Prominence HPLC system equipped with a diode array detector SPD-M20A, a column oven CTO-20AC and a pump LC-20AD SP. For oxytetracycline determination a RP-18 reversed phase Purospher STAR column $(250 \times 4 \mathrm{~mm}$ (i.d.), $5 \mu \mathrm{m}$ ) was used and the elution was performed isocratically with an oxalic acid aqueous solution (10 mM): acetonitrile, 70:30 (v/v), mixture at a flow rate of $1 \mathrm{~mL} \mathrm{~min}^{-1}$ and $30{ }^{\circ} \mathrm{C}$. The carboxylic acids determination was made by ion-exclusion chromatography using a Biorad Aminex HPX-87H column $(300 \times 7.8 \mathrm{~mm}$ (i.d.)) and the elution was performed isocratically with a sulfuric acid aqueous solution $(4 \mathrm{mM})$ at a flow rate of $0.6 \mathrm{~mL} \mathrm{~min}^{-1}$ and $35{ }^{\circ} \mathrm{C}$. The selected wavelength was $354 \mathrm{~nm}$ for oxytetracycline and $210 \mathrm{~nm}$ for carboxylic acids. The reagents used were HPLC grade and supplied by Sigma-Aldrich. All the solutions for HPLC were prepared with ultrapure water obtained with Milli-Q system. Measurements of $\mathrm{pH}$ were carried out with a Mettler-Toledo $\mathrm{pH}$ meter. Conductivity was determined using a conductivity meter Mettler Toledo (SevenEasy S30K).

Table 1. OTC chemical structure and experimental conditions used in the OTC oxidation assays.

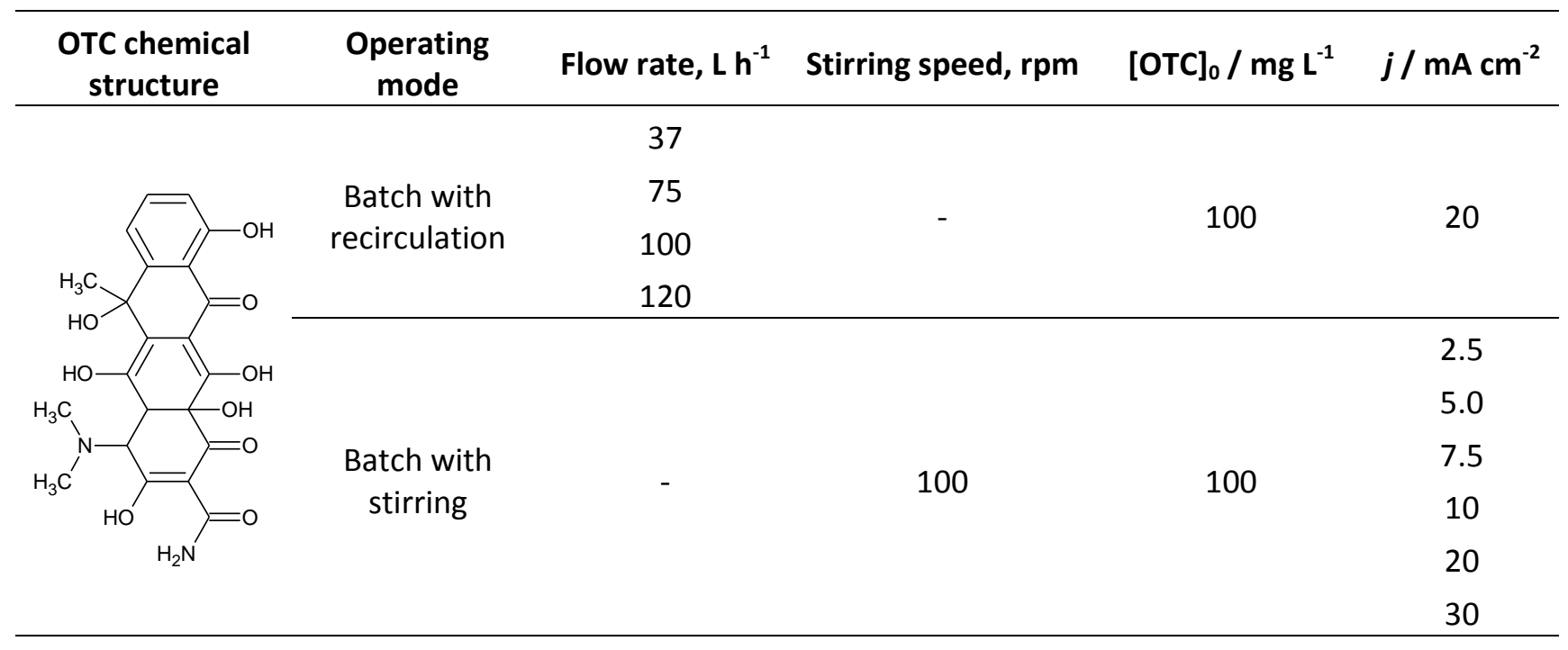

\section{Results and discussion}

Figure 1 presents variation in time of COD, TOC and OTC concentration for the first set of assays performed in batch with recirculation conditions at different flow rates. Initial COD and TOC values are slightly different for the various experiments performed, since fresh solutions were prepared for each assay to avoid OTC photodegradation, and the values presented are the mean values obtained for the different replicas. Up to $4 \mathrm{~h}$, there is a regular decay in time of COD and TOC. After that, particularly at higher flow rates, there is a decrease in the organic load removal rate. However, after $8 \mathrm{~h}$ degradation, for the flow rates tested $\left(37,75,100\right.$ and $\left.120 \mathrm{~L} \mathrm{~h}^{-1}\right)$ the remaining CODs were 17, 12, 15 and $17 \%$, and the remaining TOCs were 8, 911 and $9 \%$, respectively, meaning that the flow rates used almost didn't interfere with the organic load removal. Similar behavior was already observed by other authors $[49,50]$. On the other hand, if data for the first 4 hours assay is used to calculate the $\triangle T O C / \triangle C O D$ ratios (insets of Figure 1 ), different slopes can be 
obtained for the different flow rates, showing the influence of this parameter on the degradation mechanism. In fact, TOC vs. COD slope decreases with the increase in flow rate, showing that the increase in flow rate has a negative impact on the OTC mineralization degree at the earlier stages of the electrodegradation assay. This happens because the increase in flow rate decreases the diffusion layer width, favoring the counter diffusion of the reaction intermediate products, avoiding their complete mineralization. After $4 \mathrm{~h}$ assay, the TOC vs. COD slope changes, since the products in solution are other than OTC, as can be seen by the OTC concentration determined by HPLC.

Regarding the OTC concentration decay (Figure 1), the electrodegradation process kinetics is almost independent of the imposed flow rate. It presents a pseudo-first order kinetic and only the assay performed at the lowest flow rate shows a lower kinetic constant $\left(1.18 \mathrm{~h}^{-1}\right)$, probably due to some diffusional hindrance at low flux and to cathodic reactions that can contribute to the overall kinetic process (including COD and TOC kinetic rates).
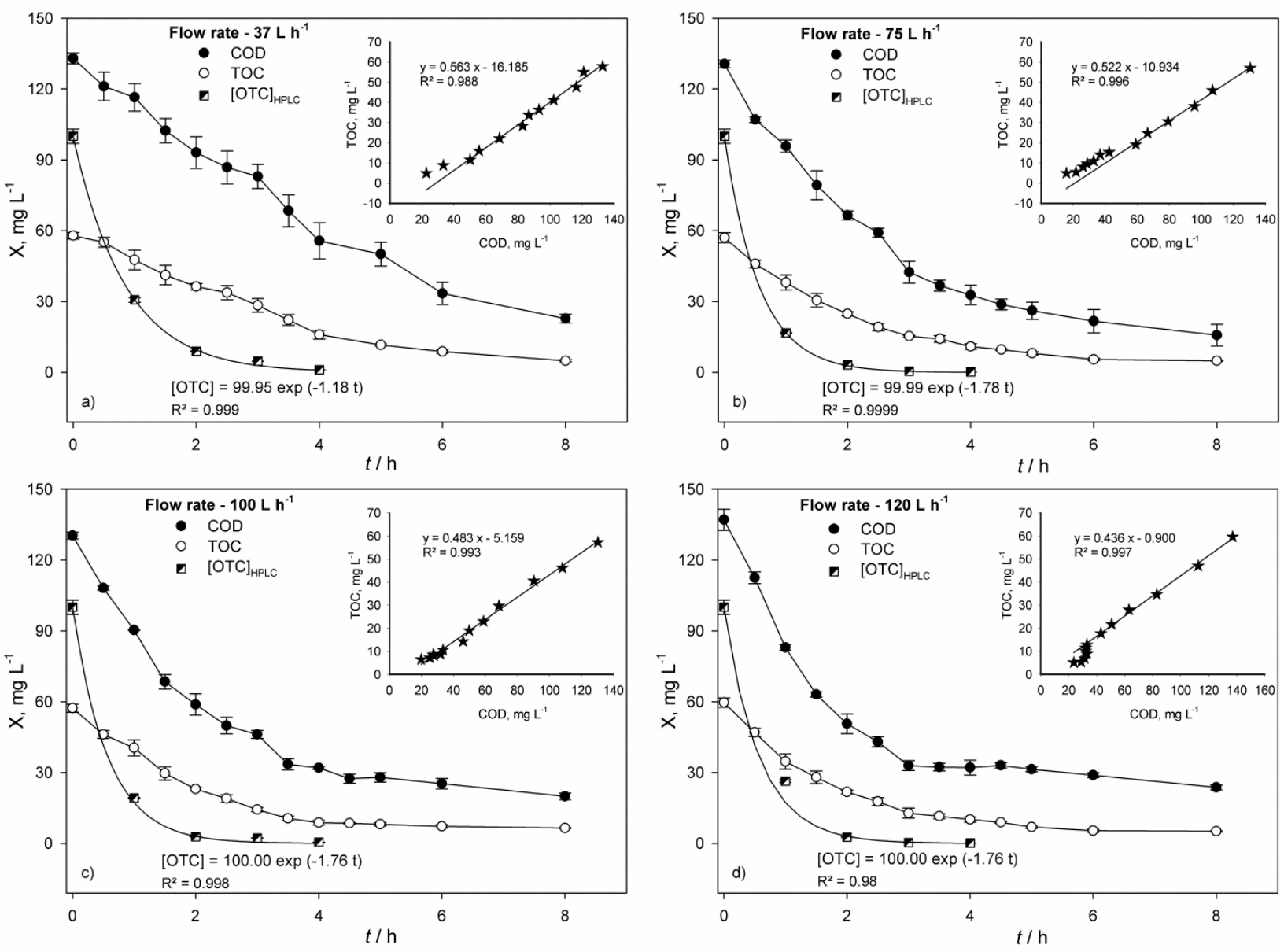

Figure 1. Variation of $C O D, T O C$ and [OTC] with time for the electrodegradation assays performed in batch with recirculation mode for the different flow rates tested. Insets: Variation of TOC with COD along time.

The samples collected during the assays were also used to run UV-Vis absorption spectra and results for the flow rates of 37 and $120 \mathrm{~L} \mathrm{~h}^{-1}$ are presented as the absorbance variation in time measured at 276 and $355 \mathrm{~nm}$, the two major OTC characteristic absorption bands (Figure 2, a and b). Similarly to COD and TOC, the absorbance decay at both wavelengths increase with flow rate, being the decay at $355 \mathrm{~nm}$ faster than at $276 \mathrm{~nm}$. This means that in the OTC molecule the ring containing the $\mathrm{N}$-groups (responsible for the absorbance at $276 \mathrm{~nm}$ ) is not so easily opened as the other rings, or the intermediate products formed also absorb at this wavelength, thus contributing to increase the absorbance at $276 \mathrm{~nm}$. 
Regarding nitrogen removal from solution (Figure $2 c$ ), there is only a very slight decay in the total nitrogen amount and an increase followed by a decrease in the ammonium nitrogen concentration during the $8 \mathrm{~h}$ assays. This means that the organic nitrogen is slowly converted into ammonium and, only when the organic load is very small, ammonium is oxidized to nitrogen volatile species, being this conversion higher for higher flow rates, probably because COD and TOC removal rates also increase with flow rate.
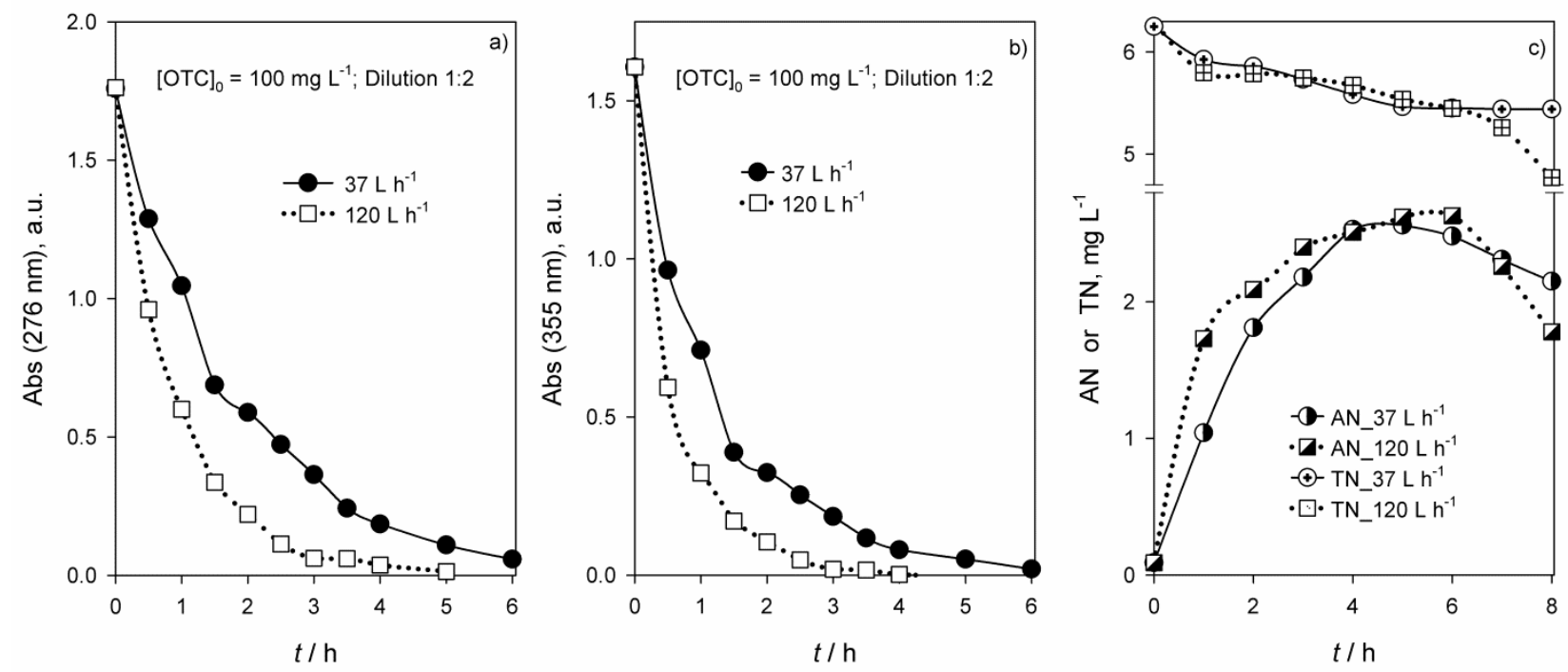

Figure 2. Variation with time of absorbance, measured at (a) 276 and (b) $355 \mathrm{~nm}$, (c) AN and $T N$ for the electrodegradation assays performed in batch mode with recirculation for two different flow rates tested: 37 and $120 \mathrm{~L} \mathrm{~h}^{-1}$.

The influence of the current density on the OTC degradation rate was studied in a stirred batch system and results for the decays in COD, TOC and absorbance, measured at 276 and $355 \mathrm{~nm}$, are presented in Figure 3. The absolute COD and TOC removals increased with current density, mainly due to the increase in indirect oxidation promoted by the hydroxyl radicals, formed when the applied current exceeds the limiting current corresponding to the organic load of the solution. Simultaneously, the formation of persulfate radicals can also happen, since sulfate was the chosen electrolyte.

The absorbance variation measured at the OTC characteristic absorption bands presents a behavior that seems dependent on the applied current density. For the lowest applied current, after $4 \mathrm{~h}$ assay there is a divergence between the absorbance curves at 276 and $355 \mathrm{~nm}$, with an increase in the absorbance at $276 \mathrm{~nm}$, meaning that products that absorb at this wavelength are being formed. These products must be resistant to oxidation, since the curve related with absorbance at $355 \mathrm{~nm}$ suffers a sudden decay that must be related with an increase in the degradation of the remaining OTC, since at this applied current density the OTC decay is slower, as will be discussed below.

For higher applied current densities, there is a separation between the absorbance curves measured at the two characteristic wavelengths that increases with the applied current density, due to reasons already discussed. This fact must also be a consequence of the different mineralization degree for the different experimental conditions, as can be observed in Figure 4. In fact, the mineralization degree decreases with applied current densities between 2.5 and $7.5 \mathrm{~mA} \mathrm{~cm}^{-2}$, showing a smaller increase for higher current densities. This behavior must be related with 
hydroxyl radicals' indirect oxidation and the diffusion hindrance promoted by the oxygen evolution at higher applied current densities.
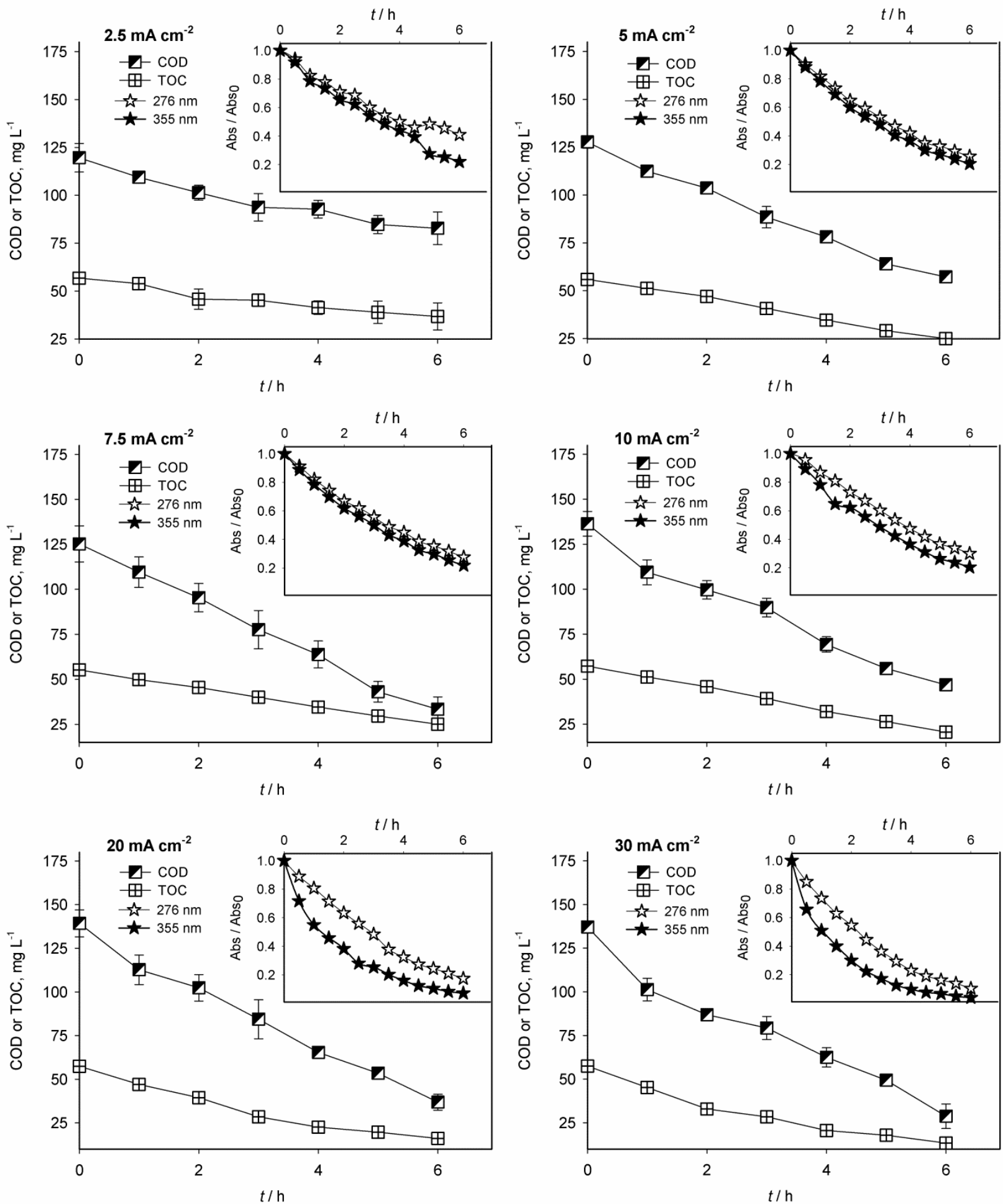

Figure 3. $C O D$ and TOC decays with time for the electrodegradation assays performed in batch with stirring mode for the different applied current densities tested. Insets: Relative absorbance decays in time, measured at 276 and $355 \mathrm{~nm}$.

Regarding the electrodegradation kinetics (Figure 5), the OTC concentration decays show a dependence on the applied current density. As previously observed for the assays run in batch mode with recirculation, it presents a pseudo-first order kinetic, with the kinetic constant (Figure 5 , symmetric of the slopes of the adjusted equations) increasing with current density. 

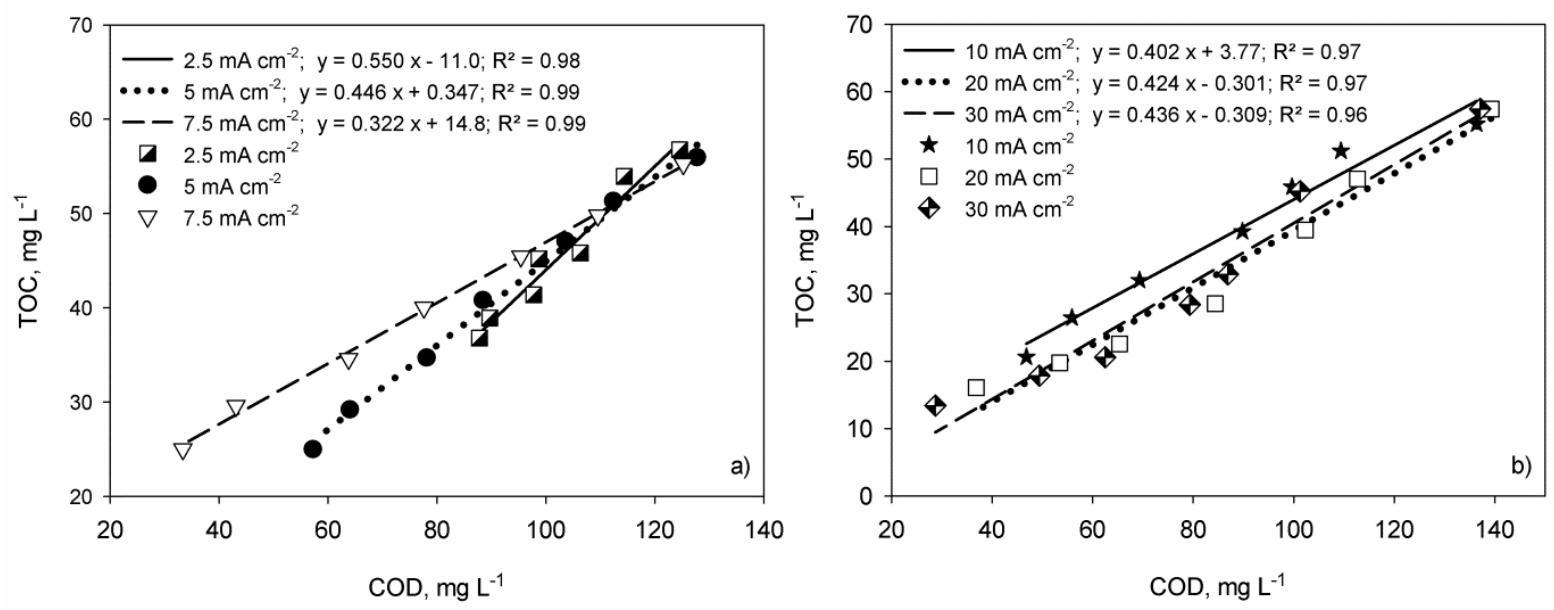

Figure 4. TOC vs COD variation for the electrodegradation assays performed in batch mode with stirring at different applied current densities.
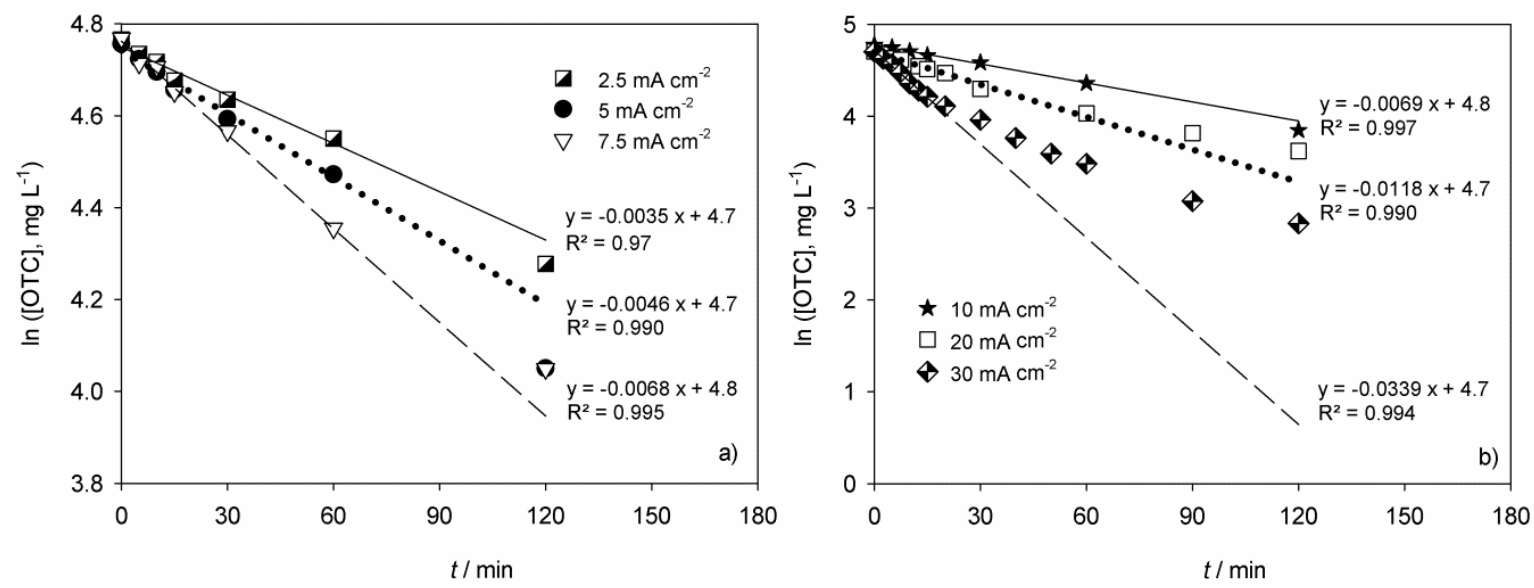

Figure 5. Variation of OTC concentration with time for the electrodegradation assays performed in batch mode with stirring at different applied current intensities.

In order to compare the values obtained in both operating systems used, the slope obtained for $20 \mathrm{~mA} \mathrm{~cm}^{-2}$ was converted to the same units as those in Figure 1, giving $0.71 \mathrm{~h}^{-1}$, showing that in the applied experimental conditions batch with stirring operating mode is less efficient than batch with recirculation mode, probably due to the importance of the OTC diffusion to the reaction zone in the degradation process.

The concentration of the main reaction intermediate products was also followed by HPLC. Besides the main carboxylic acids detected, oxalic, oxamic and maleic acids and vestiges of formic acid were also identified, particularly at higher current densities. In Figure 6, the variation in time of the oxalic, oxamic and maleic acids is presented for the current densities of $2.5,10$ and $30 \mathrm{~mA} \mathrm{~cm}^{-2}$, for the two first current densities between 0 and $8 \mathrm{~h}$ and for $30 \mathrm{~mA} \mathrm{~cm}{ }^{-2}$ between 0 and $12 \mathrm{~h}$. When OTC is the main organic compound in solution, there is an increase in those intermediates concentration. After that, their concentration start to decrease and they are mineralized. The existence of only small dicarboxylic acids with conjugated double bonds points to a degradation mechanism characteristic of indirect oxidation, where the parent molecule is attacked in many different places, leaving unchanged double conjugated bond systems, less easily oxidized. 

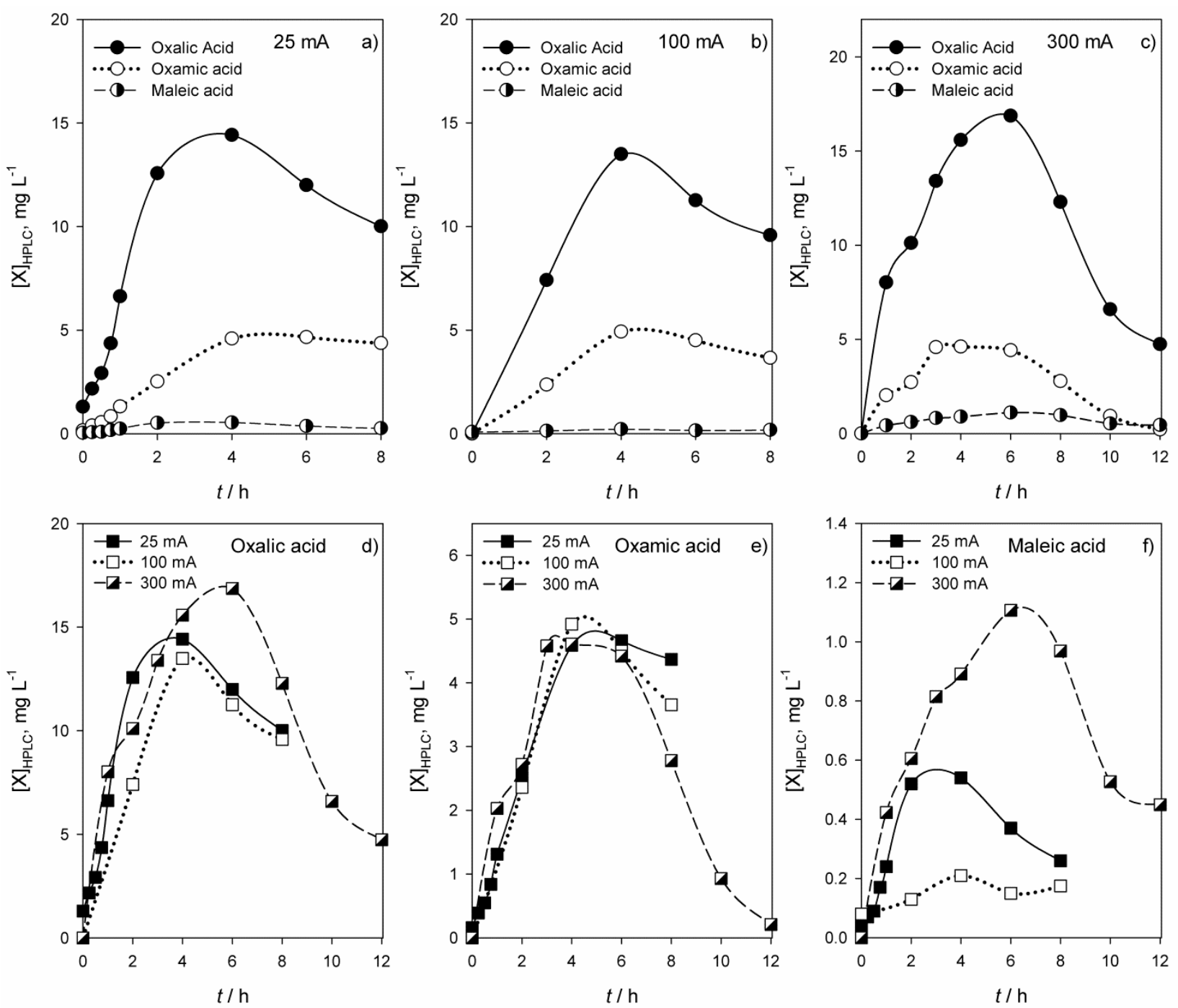

Figure 6. Influence of the current density on the variation with time of the concentration of some of the intermediate products formed during the OTC electrodegradation, performed in batch with stirring mode at different applied current intensities.

\section{Conclusions}

In this study oxytetracycline was successfully degraded through anodic oxidation with a BDD anode. The investigation of the influence of the experimental conditions on the OTC degradation allowed drawing the following conclusions:

- Degradation mechanism occurred mainly through indirect oxidation.

- COD and TOC removals increased with current density, being almost independent of the flow rates tested, meaning that the current density plays an important role in the OTC oxidation rate, mainly due to the formation of hydroxyl and persulfate radicals that are the main species responsible for the indirect OTC oxidation.

- The increase in flow rate has a negative impact on the OTC mineralization degree.

- The organic nitrogen is slowly converted into ammonium and, only when the organic load is very small, ammonium is oxidized to nitrogen volatile species, being this conversion higher for higher flow rates.

- The electrodegradation process presents pseudo-first order kinetic and the kinetic constant increases with current density. For flow rates higher than $75 \mathrm{~L} \mathrm{~h}^{-1}$, the process kinetics is almost 
independent of the imposed flow rate. However, for lower flow rate the diffusion hindrance leads to lower OTC removal rates.

- The main by-products detected were oxalic, oxamic and maleic acids, whose concentration increased while OTC was the main organic compound in solution. After that, the by-products concentration started to decrease, indicating their mineralization.

Acknowledgements: Financial support from FEDER, Programa Operacional Factores de Competitividade - COMPETE, and FCT, for the project PEst-OE/CTM/UI0195/2011 of the MTP Unit and for the grant awarded to A. Fernandes SFRH/BD/81368/2011.

\section{References}

[1] D. Bendz, N. A. Paxeus, T. R. Ginn, F. J. Loge, Journal of Hazardous Materials 122 (2005) 195-204

[2] P. H. Roberts, K. V. Thomas, Science of the Total Environment 356 (2006) 143-153

[3] S. D. Kim, J. Cho, I. S. Kim, B. J. Vanderford, S. A. Snyder, Water Research 41 (2007) 10131021

[4] T. Deblonde, C. Cossu-Leguilleb, P. Hartemanna, International Journal of Hygiene and Environmental Health 214 (2011) 442-448

[5] D. Calderón-Preciado, V. Matamoros, J. M. Bayona, Science of the Total Environment 412413 (2011) 14-19

[6] D. J. Lapworth, N. Baran, M. E. Stuart, R. S. Ward, Environmental Pollution 163 (2012) 287-303

[7] I. Chopra, M. Roberts, Microbiology and Molecular Biology Reviews 65 (2001) 232-260

[8] A. A. Borghi, M. S. A. Palma, Brazilian Journal of Pharmaceutical Sciences 50 (2014) 25-40

[9] B. Halling-Sorensen, G. Sengelov, J. Tjornelund, Archives of Environmental Contamination and Toxicology 42 (2002) 263-271

[10] B. Halling-Sorensen, S. N. Nielsen, P. F. Lanzky, F. Ingerslev, H. C. H. Lutzhoft, S. E. Jorgensen, Chemosphere 36 (1998) 357-394

[11] Q. Yang, J. Zhang, K. Zhu, H. Zhang, Journal of Environmental Sciences 21 (2009) 954-959

[12] L. Migliore, F. Godeas, S. P. De Filippis, P. Mantovi, D. Barchi, C. Testa, N. Rubattu, G. Brambilla, Environmental Pollution 158 (2010) 129-134

[13] V. Andreu, P. Vasquez-Roig, C. Blasco, Y. Picó, Analytical and Bioanalytical Chemistry 394 (2009) 1329-1339

[14] L. Zhao, Y. H. Dong, H. Wang, Science of The Total Environment 408 (2010) 1069-1075

[15] H. Kim, Y. Hong, J. Park, V. K. Sharma, S. Cho, Chemosphere 91 (2013) 888-894

[16] I. Sirés, E. Brillas, Environment International 40 (2012) 212-229

[17] L. Feng, E.D. van Hullebusch, M. A. Rodrigo, G. Esposito, M. A. Oturan, Chemical Engineering Journal 228 (2013) 944-964

[18] I. Oller, S. Malato, J. A. Sánchez-Pérez, Science of the Total Environment 409 (2011) 41414166

[19] N. A. Alonso-Salles, F. Fourcade, F. Geneste, D. Floner, A. Amrane, Journal of Hazardous Materials 181 (2010) 617-623

[20] C. Reyes, J. Férnandez, J. Freer, M.A. Mondaca, C. Zaror, S. Malato, H. D. Mansilla, Journal of Photochemistry and Photobiology A 184 (2006) 141-146

[21] I. R. Bautitz, R. F. P. Nogueira, Journal of Photochemistry and Photobiology A 187 (2007) 33-39

[22] S. Jiao, S. Zheng, D. Yin, L. Wang, L. Chen, Chemosphere 73 (2008) 377-382

[23] K. Li, A. Yediler, M. Yang, S. Schulte-Hostede, M. H. Wong, Chemosphere 72 (2008) 473-478

[24] J. Shaojun, Z. Shourong, Y. Daqiang, W. Lianhong, C. Liangyan, Journal of Environmental Sciences 20 (2008) 806-813 
[25] H. Zhang, F. Liu, W. Xiaogang, J. Zhang, D. Zhang, Asia-Pacific Journal of Chemical Engineering 4 (2009) 568-573

[26] J. Jeong, W. Song, W. J. Cooper, J. Jung, J. Greaves, Chemosphere 78 (2010) 533-540.

[27] J. J. Lopez-Peñalver, M. Sánchez-Polo, C. V. Gómez-Pacheco, J. Rivera-Utrilla, Journal of Chemical Technology and Biotechnology 85 (2010) 1325-1333

[28] H. Lee, E. Lee, C.H. Lee, K. Lee, Journal of Industrial and Engineering Chemistry 17 (2011) 468-473

[29] M. Miyata, I. Ihara, G. Yoshid, K. Toyod, K. Umetsu, Water Science \& Technology 63 (2011) 456-461

[30] C. I. Brinzila, M.J. Pacheco, L. Ciríaco, R. C. Ciobanu, A. Lopes, Chemical Engineering Journal 209 (2012) 54-61

[31] R. Daghrira, P. Droguia, I. Kab, M. A. El Khakanib, Journal of Hazardous Materials 199-200 (2012) 15-24

[32] C. V. Gómez-Pacheco, M. Sánchez-Polo, J. Rivera-Utrilla, J.J. Lopez-Peñalver, Chemical Engineering Journal 187 (2012) 89-95

[33] L. Hou, H. Zhang, X. Xue, Separation and Purification Technology 84 (2012) 147-152

[34] J. Wu, H. Zhang, N. Oturan, Y. Wang, L. Chen, M.A. Oturan, Chemosphere 87 (2012) 614-620

[35] D. Bu, H. Zhuang, Applied Surface Science 265 (2013) 677-685

[36] N. Oturan, J. Wu, H. Zhang, V. K. Sharma, M. A. Oturan, Applied Catalysis B: Environmental 140-141 (2013) 92-97

[37] C. I. Brinzila, N. Monteiro, M.J. Pacheco, L. Ciríaco, I. Siminiceanu, A. Lopes, Environmental Science and Pollution Research, DOI 10.1007/s11356-014-2778-y

[38] C. A. Martínez-Huitle, E. Brillas, Applied Catalysis B: Environmental 87 (2009) 105-145

[39] M. Panizza, G. Cerisola, Chemical Reviews 109 (2009) 6541-6569

[40] L. Jiancheng, Y. Jie, L. Weishan, H. Qiming, X. Hongkang, Journal of Electrochemical Science and Engineering 2(4) (2012) 171-183

[41] A. N. S. Rao, V.T. Venkatarangaiah, Journal of Electrochemical Science and Engineering 3 (2013) 167-184

[42] C. C. Jara, D. Fino, V. Specchia, G. Saracco, P. Spinelli, Applied Catalysis B: Environmental 70 (2007) 479-487

[43] A. Morão, A. Lopes, M.T. Pessoa de Amorim, I.C. Gonçalves, Electrochimica Acta 49 (2004) 1587-1595

[44] M. Panizza, G. Cerisola, Electrochimica Acta 51 (2005) 191-199

[45] M.J. Pacheco, A. Morão, A. Lopes, L. Ciríaco, I. Gonçalves, Electrochimica Acta 53 (2007) 629-636

[46] L. Círiaco, C. Anjo, J. Correia, M. J. Pacheco, A. Lopes, Electrochimica Acta 54 (2009) 1464-1472

[47] A. El-Ghenymy, P.L. Cabot, F. Centellas, J. A. Garrido, R. M. Rodríguez, C. Arias, E. Brillas, Electrochimica Acta 90 (2013) 254-264

[48] A. Eaton, L. Clesceri, E. Rice, A. Greenberg, M. A. Franson, Standard Methods for Examination of Water and Wastewater, twenty-first ed., American Public Health Association, Washington, DC, 2005

[49] J. L. Nava, I. Sires, E. Brillas, Environmental Science and Pollution Research 21(14) (2014) 8485-8492

[50] J. L. Nava, A. Recendiz, J. C. Acosta, I. Gonzalez, Water Science and Technology 58(12) (2008) 2413-2419

(C) 2014 by the authors; licensee IAPC, Zagreb, Croatia. This article is an open-access article distributed under the terms and conditions of the Creative Commons Attribution license

(http://creativecommons.org/licenses/by/3.0/) (cc) EY 